\title{
Detrimental impacts of toxic Microcystis aeruginosa from Vietnam on life history traits of Daphnia magna
}

\author{
Anh hương tiêu cưc của loài Microcystis aeruginosa có độc ở Việt Nam lên các \\ đặc điểm vòng đời của Daphnia magna
}

Research article

\begin{abstract}
Vo Thi My Chi ${ }^{1}$; Pham Thanh Luu ${ }^{2}$; Dao Thanh Son ${ }^{1 *}$
${ }^{1}$ Hochiminh City University of Technology, 268 Ly Thuong Kiet Street, District 10, Hochiminh City, Vietnam; ${ }^{2}$ Vietnam Academy of Science and Technology (VAST), Institute of Tropical Biology, 85 Tran Quoc Toan Street, District 3, Hochiminh City, Vietnam
\end{abstract}

\begin{abstract}
In this study, we tested the long-term and negative effects of microcystin-producing cyanobacterium Microcystis aeruginosa from Vietnam on Daphnia magna under the laboratory conditions. The test organisms were fed with mixtures of green alga Scenedesmus armatus. and toxic M. aeruginosa at different ratios (10\% Microcystis $+90 \%$ Scenedesmus, 50\% Microcystis $+50 \%$ Scenedesmus, $100 \%$ Microcystis, and $100 \%$ Scenedesmus) for over a period of 21 days. The life history traits of the organisms such as, survival, maturation, fecundity were daily recorded. Besides, the intrinsic population rate of $D$. magna in each treatment was also calculated based on the survivorship, the reproductive age and the clutch size of the animals. The results showed that survival, maturation and reproduction of the D. magna fed with 10,50 and $100 \% M$. aeruginosa was impaired. Additionally, the intrinsic population rate of the exposed D. magna was lower than that of the control. This study evidenced the adverse effects of toxic $M$. aeruginos $a$ on both the individual and intrinsic population levels of $D$. magna. To our knowledge, this is the first report on the chronically detrimental impacts of toxic M. aeruginosa isolated from Vietnam on D. magna and contributed the scientific information on the severe influences of toxic cyanobacteria world wide.
\end{abstract}

Trong bài viết này, chúng tôi nghiên cưu ảnh hưởng xấu mãn tính của loài vi khuẩn lam Microcystis aeruginosa có khả năng sản sinh độc tố microcysin tùu Việt Nam lên Daphnia magna trong điều kiện phòng thí nghiệm. Sinh vật thí nghiệm được cho ăn với hốn hợp tảo luc Scenedesmus armatus và M. aeruginosa có độc ở các tỷ lẹ khác nhau (10\% Microcystis + 90\% Scenedesmus, 50\% Microcystis $+50 \%$ Scenedesmus, $100 \%$ Microcystis, và 100\% Scenedesmus) trong thời gian 21 ngày. Các đặc điểm vòng đời của sinh vật bao gồm sức sống, sự thành thục, sức sinh sản được theo dõi hàng ngày. Bên cạnh đó, tỷ lệ phát triển quần thể của D. magna trong tùng lô thí nghiệm cũng được tính toán dựa vào sức sống, tuổi sinh sản và kích cõ sinh sản của sinh vật. Kết quả cho thấy, sức sống, tuổi thành thuc và sụ sinh sản của D. magna cho ăn với 10,50 và $100 \%$ M. aeruginosa bi ảnh huởng xấu. Bên cạnh đó, tỷ lệ phát triển quần thể của D. magna trong lô phơi nhiếm thấp hơn so với đối chưng. Nghiên cúu này chứng minh ảnh hưởng xấu của M. aeruginosa có độc lên cả hai mức độ cá thể và quần thể của D. magna. Theo hiểu biết của chúng tôi, đây là báo cáo đầu tiên về ảnh hưởng xấu mãn tính của M. aeruginosa có độc phân lập tù̀ Việt Nam lên D. magna and đóng góp thêm thông tin khoa học cho những ảnh hưởng nghiêm trọng của vi khuẩn lam có độc trên khắp thế giới.

Keywords: life history traits, microcystins, Daphnia magna, Microcystis aeruginosa, negative effects 


\section{Introduction}

Eutrophication is known to cause and enhance the cyanobacterial mass development. Seriously, cyanobacteria are capable of producing toxic metabolites and bioactive compounds such as microcystins (MCs), anatoxin-a, cylindrospermopsin, among others (Sinoven et al., 1999; Banker et al., 1999; Rohrlack et al., 2003) of which MCs are the most common and potent cyanobacterial toxins in freshwater bodies (Doekel et al., 2001).

Many investigations have showed that cyanobacteria and their toxins are extremely toxic to aquatic organisms, and the toxicity investigations have focused on the effects of Microcystis on Daphnia over the last few decades. For example, in the laboratory condition, the mortality of Daphnia increased when fed on MCs-producing cyanobacteria and purified microcystin-LR. Additionally, the effective rate strongly depended on the concentration of exposure and the sensitivity of species (Demott and Moxter, 1991; Trubetskova and Haney, 2006). Also, there have been evidences that the feeding rate was inhibited, and the growth rate and reproduction were decreased when the daphnids were priorly fed with toxic Microcystis (DeMott, 1999). In spite of not including any toxic impacts, the negative effects of some Microcystis strains on body length, fecundity (number of new born per female) and clearance rate of Daphnia were recorded (Lürling and Van der Grinten, 2003; Lürling, 2003).

In recent years, researchers have cared about the maternal effects of cyanobacteria and their toxins on zooplankton. If cyanobacteria and their toxins reside inside the body of Daphnids for a longer period of time, it can be transferred to their offspring. Guo and Xie (2006) proved the tolerance development against toxic $M$. aeruginosa of Ceriodaphnia cornuta, Moina micriura, but Daphnia carinata after exposed trans-generationally to mixture of Scenedesmus and toxic or non-toxic Microcystis for 4 weeks. Dao et al. (2010) investigated in detail chronic effects of cyanobacterial toxins, with emphasis on MCs, on D. magna. The low concentration of MC-LR slightly affected the growth and reproduction of parent daphnids. Survivor decreased during chronic exposure with increasing MCs concentration. Age to maturity of the offspring increased and their survival decreased after parent generation was exposed to the toxin, even if the offspring were raised in non-toxic medium. Besides, cessation of the egg/embryos was observed and malformation of neonates caused by cyanobacterial toxins was firstly recorded. In the other reports, mother Daphnia exposed to MCs resulted in the decrease in dry mass of its offspring even though they were raised in nontoxic medium (Ortiz-Rodriguez et al, 2012).

The occurrence of cyanobacteria in lakes and reservoirs can cause potential risks to aquatic organisms. In Vietnam, the studies of cyanobacteria have focused only on morphological taxonomy and concentration or toxin producing cyanobacteria (Shirota, 1966; Pham, 1969; Nguyen, 1983, 1997; Phung et al., 1992; Duong, 1996; Dang et al., 2000; Hummert et al., 2001). Additionally, there is little information in the literature about the negative effects of cyanobacteria from Vietnam on micro-crustaceans. Therefore, in this study, we aimed to investigate the long-term effects of cyanobacteria containing MCs isolated from Vietnam on the life history traits of $D$. magna.

\section{Materials and methods}

\subsection{The test organisms}

Daphnia magna Straus was purchased from the MicroBioTests Inc, Belgium (Fig. 1). The animal has been fed with green alga Scenedesmus armatus and maintained in the laboratory conditions of $22 \pm 1{ }^{\circ} \mathrm{C}$, dim light and light dark cycle of 14h:10h. Microcystis aeruginosa was used for exposure to D. magna. The cyanobacterium $M$. aeruginosa (Fig. 1) was isolated from Dau Tieng Reservoir, a drinking water supply $120 \mathrm{~km}$ western Hochiminh City, Vietnam. Both cyanobacterium and green alga were cultivated in Z8 medium (Kotai, 1972) with continuous aeration and under the laboratory conditions of $25 \pm 1^{\circ} \mathrm{C}$, light intensity of around 3000 Lux, and light dark cycle of $12 \mathrm{~h}: 12 \mathrm{~h}$.

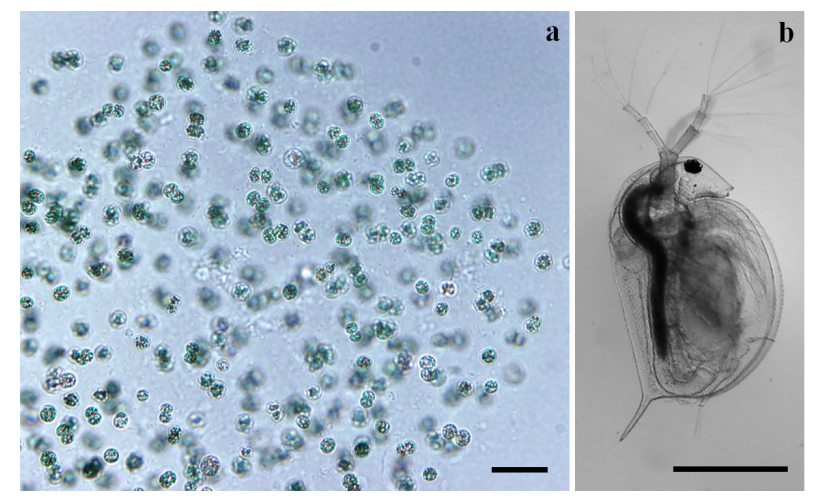

Figure 1. The organisms for the toxicity test. a, Microcystis aeruginosa; b, newly born Daphnia magna. Scale bar of $a=20 \mu \mathrm{m}$, and $b=300 \mu \mathrm{m}$.

\subsection{Toxin analysis}

The culture of M. aeruginosa was harvested during the exponential growth phase and filtered onto GF/A filters (Fiore, France), dried at $50^{\circ} \mathrm{C}$ over night and stored at $-70^{\circ} \mathrm{C}$ prior to toxin determination. For MCs determination, the filters containing microbes were cut into small pieces with scissors. Extraction of MCs was conducted according to Barco et al. (2005) with minor modification. Briefly MCs were firstly extracted in $5 \mathrm{~mL}$ of $100 \%$ (vol/vol) aqueous methanol by shaken for $60 \mathrm{~min}$ followed by $2 \times 60 \mathrm{~min}$ of extraction in $3 \mathrm{~mL}$ of $75 \%$ aqueous methanol. Each extraction step was followed by centrifugation $(4.500 \mathrm{rpm}, 30$ $\left.\min , 4^{\circ} \mathrm{C}\right)$. The supernatants of all extractions from each sample were pooled, dried at room temperature, re-dissolved in $0.5 \mathrm{~mL} \mathrm{MeOH} \mathrm{(100 \% )} \mathrm{and} \mathrm{centrifuged} \mathrm{at} 8.000$ $\mathrm{rpm}, 4^{\circ} \mathrm{C}$ for 5 minutes. The supernatant was passed through a Minisart RC 4 filter membrane $(0.20 \mu \mathrm{m}$ pore size, Sartorius Stedim Biotech, Germany), and kept at $20^{\circ} \mathrm{C}$ prior to reversed phase HPLC for analysis. Reverse phase HPLC (Shimadzu 10A series, Shimadzu, Kyoto, Japan) equipped with a silica based reverse phase $\mathrm{C}_{18}$ column (Waters SunFire ${ }^{\mathrm{TM}} 5 \mu \mathrm{m}, 3.0 \times 250 \mathrm{~mm}$, Ireland), maintained at $40^{\circ} \mathrm{C}$. A $0.05 \mathrm{M}$ phosphate buffer $(\mathrm{pH} 2.5)$ in methanol $(50 / 50, \mathrm{v} / \mathrm{v})$ was used as mobile phase, at a flow rate of $0.58 \mathrm{~mL} \mathrm{~min}^{-1}$. MC congeners were detected by the 
UV detection at $238 \mathrm{~nm}$ with a photodiode UV-visible array detector. Microcystin-LR, -RR and -YR purchased from Wako chemicals company (Osaka, Japan) were used as standards. The HPLC system had a detection limit of $0.01 \mu \mathrm{g} \mathrm{L}^{-1}$.

\subsection{Experimental setup}

Fifteen neonates $(<24 \mathrm{~h}$ old $)$ were used for each chronic experiment (Adema, 1978) and individually raised in 50 $\mathrm{mL}$ beakers containing $20 \mathrm{~mL}$ of medium (Dao et al., 2010). In the control experiment, the Daphnia was fed with $100 \%$ of green alga $S$. armatus at the concentration of $1 \mathrm{mg}$ $\mathrm{C} \mathrm{L}^{-1}$ day $^{-1}$ (Gustafsson et al., 2005). In exposures, Daphnia was fed with a mixture of Scenedesmus and cyanobacterium $M$. aeruginosa with total concentration of $1 \mathrm{mg} \mathrm{C}$ $\mathrm{L}^{-1} \mathrm{day}^{-1}$, at three different regimes (1) $10 \%$ Scendesmus + 90\% Microcystis; (2) 50\% Scenedesmus + Microcystis; and (3) $100 \%$ Microcystis (Table 1). In total, four incubations including one control and three different exposures (Table 1) were run under the temperature of $22 \pm 1^{\circ} \mathrm{C}$, dim light and light dark cycle of $14 \mathrm{~h}$ : $10 \mathrm{~h}$.

All medium and food were renewed every two days. The life history traits of Daphnia such as survival, maturity age, reproduction were daily observed during 21 days. Besides, age specific survival and clutch size were used to estimate the intrinsic rate of population increase, $r$, as a measure of fitness. The Euler equation (Stearns, 1992) was used to calculate $\mathrm{r}$ :

$$
1=\sum e^{-r x} l_{x} m_{x}
$$

Where $\mathrm{x}$ is age (in days), $1_{\mathrm{x}}$ is the probability of surviving and $m_{x}$ is the fecundity at age $x$

Table 1. Summary of the treatments in the toxicity test

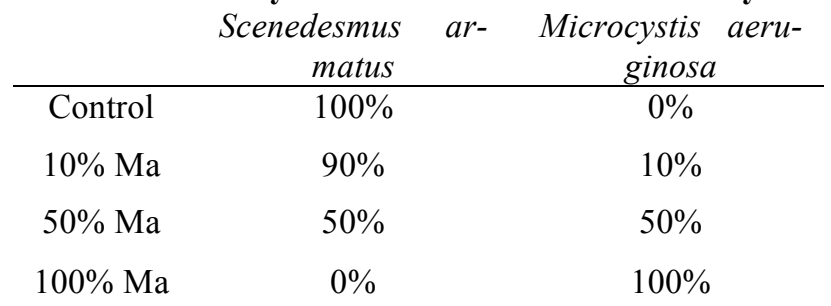

\subsection{Statistical analysis}

Sigmaplot version 12 was used for the data treatment. Kruskal-Wallis test was applied for calculation on statistically significant difference of the maturation of D. magna. P-values less than 0.05 were considered statistically significant.

\section{Results and discussion}

\subsection{Microcystins concentration in the M. aeru- ginosa}

The results of HPLC analysis showed that the $M$. aeruginosa strain produced MC-RR with the concentration of $3733 \mu \mathrm{g} \mathrm{g}^{-1}$ dry weight (Fig. 2). Along with MC-LR, MC$\mathrm{RR}$ is the most frequent MC variant, which posses a grave threat to both environment safety and public health (Zhang et al., 2007). This concentration of MCs was comparable with the results in previous the studies (e.g. Nguyen et al., 2007; Vasconcelos et al., 1996), in which the highest MCs

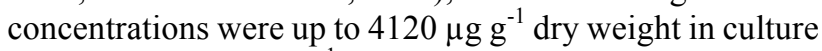
and $1000-7100 \mu \mathrm{g} \mathrm{g}^{-1}$ dry weight in natural lakes, reservoirs and rivers. The high MCs-producing $M$. aeruginosa proposed a serious risk to local residents who daily use the water from Dau Tieng reservoir for domestic activities.

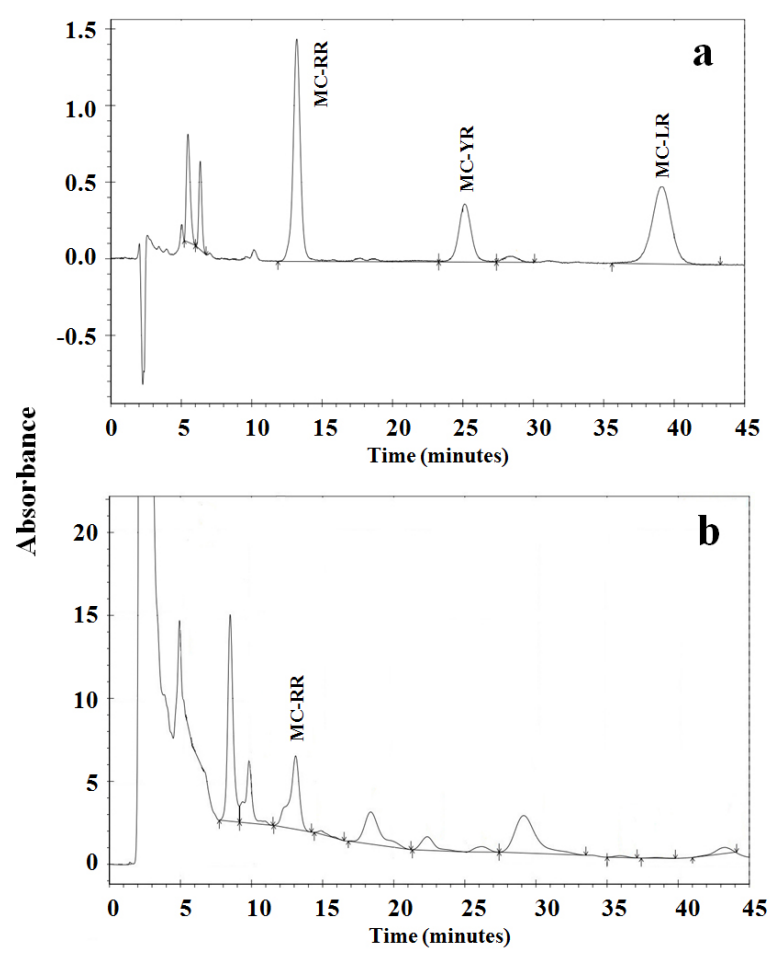

Figure 2. The HPLC chromatography of standards (a) and Microcystis aeruginosa (b)

\subsection{Effects of $M$. aeruginosa on the survivor- ship of D. magna}

In the control, all D. magna were well alive by the end of experiment. However, Daphnia started to die within approximately 1 week in all Microcystis treatments (Fig. 3). By the end of incubation, the Daphnia exposed to $10 \%$ and $50 \%$ Microcystis decreased their survival proportion to $47 \%$ and $33 \%$, respectively. The survivor proportion was lowest in the treatment of $100 \%$ Microcystis (27\%, Fig. 3) evidencing that toxic Microcystis had a strong impact on survival of Daphnia with concentration dependence. The current record was in agreement with the investigation of Dao et al. (2010), in which survivor of D. magna was $10 \%$ and $55 \%$ in 5 and $50 \mu \mathrm{g} \mathrm{MC} \mathrm{L} \mathrm{L}^{-1}$ treatments within 2 months, respectively. With the MCs concentration of 3733 $\mu \mathrm{g} \mathrm{g}^{-1}$ dry weight (as mentioned above) and the concentration of $M$. aeruginosa used for the test $\left(0.1-1 \mathrm{mg} \mathrm{C} \mathrm{L}^{-1}\right)$, the MCs concentrations in the treatments of our study were not more than $0.013 \mu \mathrm{g} \mathrm{MC} \mathrm{L}^{-1}(100 \%$ Microcystis treatment). However, the survivorship of the exposed D. magna decreased so strong (up to $73 \%$ in $100 \%$ Microcystis treatment). This could be explained as (i) the cyanobacterium used in the experiment was live cells and cyanobacteria were considered to be low nutritional value for zooplankton, mainly due to the absence of essential polyunsaturated fatty acid (PUTA) and sterols (Brett and Muller-Navarra, 1997; Von Elert, 2002), and (ii) beside MCs, Microcystis could produce other toxic bioactive compounds which 
need further investigation and chemical analysis with modern equipment (e.g. LC/MS, GC/MS) to confirm.

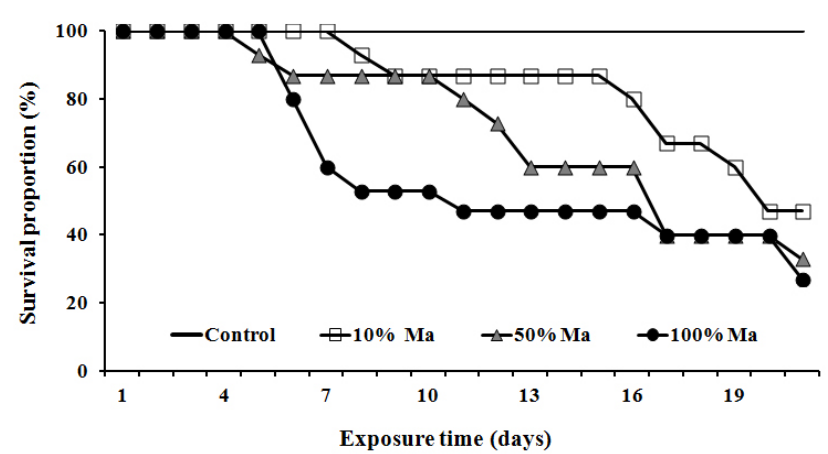

Figure 3. Survival of $D$. magna from control and exposures during 21 days of incubation. Abbreviation as in Table 1.

\subsection{Effects of M. aeruginosa on the maturation of $D$. magna}

Daphnia raised in control reached its maturity at the age of around 6 days old. However, the animals fed with toxic $M$. aeruginosa significantly delayed their maturation to the ages from $10-11$ days (Fig. 4). Seriously, some organisms in the Microcystis treatments were not able to reach their maturation although they were alive during 21 days of experiment. The negative effect of MCs on maturation of the tested organisms in this study was similar to the investigation of Dao et al. (2010).

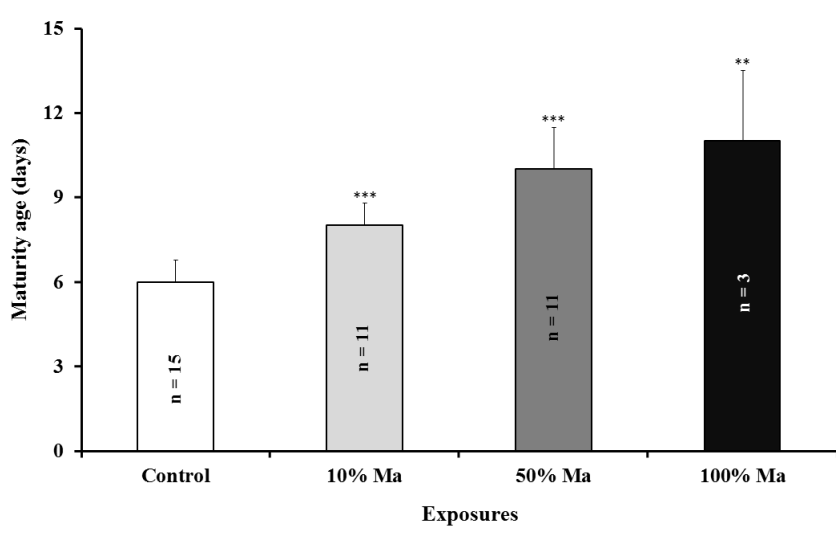

Figure 4. Maturation of $D$. magna (mean value \pm SD of $n$ as indicated in the columns) from control and exposures during 21 days of incubation. Asterisks indicate significant difference by Kruskal-Wallis test (**, p < $0.01 ; * *, p<0.001)$. Abbreviation as in Table 1 .

Some studies reported that cyanobacteria do not have enough nutrient and energy for development and maturation of the animals, mainly due to the absence of essential polyunsaturated fatty acids (PUFA) and sterols (Bret and Muller-Navarra, 1997; Von Elert, 2002). Therefore, the mal-nutrient effect should be the root for the maturation postponement of D. magna in $100 \%$ Microcystis treatment of our study. However, as green alga Scenedesmus is a good food for Daphnia, the delayed maturation in 10\% and $50 \%$ Microcystis treatments could be partly because of the mal-nutrient and partly because of toxic compounds in the Microcystis cells (e.g. MC-RR, and other bioactive compounds) affecting the animal physiology. Additionally, during the experiment, we observed the smaller body size of the Microcystis exposed Daphnia compared to the control. Green (1956) and Ebert (1991) reported that smaller Daphnia took more instars to mature consequently late maturation than the larger Daphnia.

\subsection{Effects of $M$. aeruginosa on the reproduc- tion of D. magna}

In the control, the clutch size of mother D. magna was around 10 offspring. However, the clutch size of mother $D$. magna was decreased by in Microcystis treatments. The average number of offspring per clutch in both $10 \%$ and $50 \%$ Microcystis treatments were approximately 5 individuals whereas that in $100 \%$ Microcystis treatment was only 1 individual (Fig. 5).

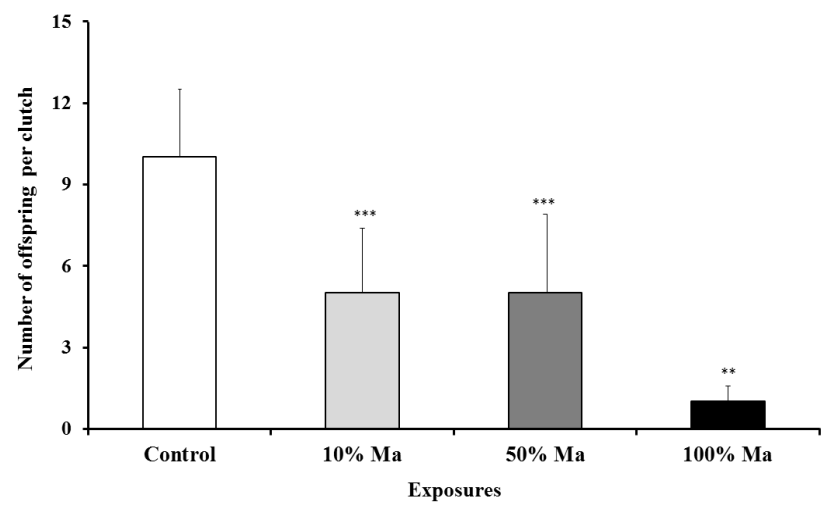

Figure 5. Fecundity of $D$. magna (mean value \pm SD of $n$ as indicated in the columns) from control and exposures during 3 weeks of incubation. Asterisks indicate significant difference by Kruskal-Wallis test $(* *, p<$ $0.01 ; * * *, p<0.001)$. Abbreviation as in Table 1.

The Kruskal-Wallis test again indicated the significant effects between the Microcystis treatments and control $(\mathrm{p}<$ 0.01 , Fig. 5). In addition, during three weeks of experiment, the total accumulative offspring in the control were highest, 637 offspring. However, that in the Microcystis treatments decreased considerably. In the exposures to $10 \%, 50 \%$ and $100 \%$ Microcystis treatments, the total offspring were 97,83 and 4, respectively (Table 2 ).

Table 2. Accumulative neonates of $D$. magna after three weeks of incubation. Abbreviation as in Table 1

\begin{tabular}{ccccc} 
& Control & $10 \% \mathrm{Ma}$ & $50 \% \mathrm{Ma}$ & $100 \% \mathrm{Ma}$ \\
\hline Total offspring & 637 & 97 & 83 & 4
\end{tabular}

The record in our study revealed negative effects of $M$. aeruginosa on Daphnia reproduction which are in line with previous investigations (Lürling and Van der Grinten, 2003; Dao et al., 2010). This result showed the seriously effects of MCs on population development for the next generations. Therefore, population of D. magna may be strongly reduced in case of cyanobacterial bloom lasting for a long time, consequently aquatic ecosystem may be unbalance, which needs further in situ investigation.

\subsection{Effects of $M$. aeruginosa on the intrinsic population rate of $D$. magna}


As mentioned above, the Microcystis strongly affected on survivor, maturity and reproduction of the animals, consequently effects on the intrinsic population rate. Daphnia in all Microcystis treatments had significantly lower intrinsic rate of population than the control. The intrinsic population rate of Daphnia in the control was 0.295 whereas those in $10 \%, 50 \%$ and $100 \%$ Microcystis treatments were 0.127 , $0.041,0.003$, respectively (Fig. 4). This result is in line with results of previous investigations reporting the negative effects of Microcystis on fitness of D. magna (de Bernardi and Guisanni, 1990; Gustafson et al., 2005).

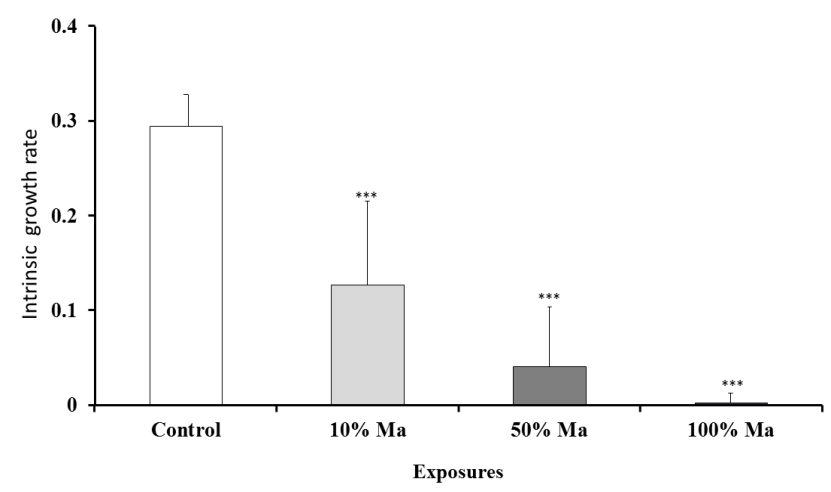

Figure 5. The intrinsic growth rate of $D$. magna (mean value \pm SD of $n$ as indicated in the columns) from control and exposures during 3 weeks of incubation. Asterisks indicate significant difference by Kruskal-Wallis test $(* *, \mathbf{p}<0.01 ; * * *, \mathbf{p}<0.001)$. Abbreviation as in Table 1.

\section{Conclusions}

The M. aeruginosa strain from the Dau Tieng Reservoir produced a high MCs concentration. Our study proved the negative effects of living cells of toxic $M$. aeruginosa on life history traits of $D$. magna including survival reduction, maturation delay, reproduction inhibition and intrinsic population rate reduction. To our knowledge, this is the first report on the chronically detrimental impacts of $M$. $a e$ ruginosa strain isolated from Vietnam on D. magna. The MCs or some bioactive compounds in cyanobacteria posed a serious risk to D. magna in particular and to aquatic organisms in general. Therefore, more attention to the presence, distribution in nature and impacts of cyanobacterial blooms on aquatic organisms should be paid to protect the aquatic environment quality and ecosystem balance.

\section{Acknowledgement}

This research is funded by Hochiminh City University of Technology - VNU-HCM and CARE-RESCIF initiative under grant number Tc-MTTN-2016-04, and Vietnam National Foundation for Science and Technology Development (NAFOSTED) under grant number 106-NN.042014.69.

\section{References}

[1] Adema, D.M.M., 1978. Daphnia magna as a test animal in acute and chronic toxicity tests. Hydrobiologia 59, 125-134.

[2] Banker, R., Carmeli, S., 1999. Inhibitors of serine proteases from a waterbloom of the cyanobacterium Microcystis sp. Tetrahedron 55, 10835-10844.

[3] Barco, M., Lawton, L.A., Rivera, J., Caixach, J., 2005. Optimization of intracellular microcystin extraction for their subsequent analysis by high-performance liquid chromatography. Journal of Chromatography A 1074(1-2), 23-30.

[4] Brett, M.T., Muller-Navarra, D.C., 1997. The role of highly unsaturated fatty acids in aquatic food web processes. Freshwater Biology 38 (3), 483-499.

[5] Dang, H.P.H., Duong, T.T., Dang, D.K., Nguyen, S.N., Hummert, C., 2000. Toxicity and toxins of some Microcystis aeruginosa strains isolated from Hoan Kiem Lake and Thanh Cong Lake. Biological Basic Researches 71-74.

[6] Dao, T.S., Do-Hong, L.C., Wiegand, C., 2010. Chronic effects of cyanobacterial toxins on Daphnia magna and their offspring. Toxicon 50, 1244-1254.

[7] De Bernardi, R., and Giussani, G., 1990. Are bluegreen algae a suitable food for zooplankton? An overview. Hydrobiologia 200/201,29-41.

[8] DeMott, W.R., 1999. Foraging strategies and growth inhibition in five daphnids feeding on mixtures of a toxic cyanobacterium and a green alga. Freshwater Biology 42, 263-274.

[9] Doekel, S. and Marahiel, M.A., 2001. Biosynthesis of natural products on molecular peptide synthetases. Methabolic Engeneering 3, 64-77.

[10] Duong, D.T., 1996. Taxonomy of cyanobacteria of Vietnam. Agriculture Publishing House Hanoi, 1220 .

[11] Ebert, D., 1991. The effects of size at birth, maturation, threshold and genetic difference on the life-history of Daphnia magna. Oecologia 86, pp. 143-250.

[12] Green, J., 1956. Growth, size and reproduction in Daphnia (Crustacea, Cladocera). Proc. Zool. Soc. Lond. 126, pp. 173-204.

[13] Guo, N., Xie, P., 2006. Development of tolerance against toxic Microcystis aeruginosa in three cladocerans and the ecological implications. Environmental Pollution 143, 513-518.

[14] Gustafsson, S., Rengefors, K., Hansson, L.-A., 2005. Increased consumer fitness following transfer of toxin tolerance to offspring via maternal effects. Ecology $86,2561-2567$.

[15] Hummert, C.J., Dahlmann, K., Reinhardt, H.P.H., Dang, D.K., Dang, Luckas, B., 2001. Liquid chromatography - mass spectrometry identification of microcystins in Microcystis aeruginosa strains from Lake Thanh Cong, Ha Noi, Vietnam. Chromatographia 54, 569-575.

[16] Kotai, J., 1972. Instructions for preparation of modified nutrient solution Z8 for algae. Norwegian Institute for Water research Oslo B-11/69, 1-5.

[17] Lürling, M., 2003. Daphnia growth on microcystin- 
producing and microcystin-free Microcystis aeruginosa in different mixture with the green alga Scenedesmus obliquus. Limnol. Oceanogr. 48, 22142220 .

[18] Lürling, M., Van der Grinten, E., 2003. Life-history characteristics of Daphnia magna exposed to dissolved microcystin-LR and to the cyanobacterium Microcystis aeruginosa with and without microcystins. Environ. Toxicol. Chem. 22, 1281-1287

[19] Nguyen, L.T.T., 2007. Planktic cyanobacteria from freshwater localities in ThuaThien-Hue province, Vietnam. PhD Thesis, Copenhagen.

[20] Nguyen, T.T., 1983. Algae from the central-highland of Vietnam. Annals of Hochiminh City University, 113-118.

[21] Nguyen, T.T., 1997. The freshwater algae of Nam Cat Tien National Park. Bulletin of Natural Sciences, No. $1,57-72$.

[22] Ortiz-Rodriguez, R., Dao, T.S., Wiegand, C., 2012. Transgenerational effects of microcystin-LR on Daphnia magna. Journal of Experimental Biology 215, 2795-2805.

[23] Pham, H.H., 1969. Quelques algues d'eau douce de la région de Can Tho. Annals of the University of Cantho. Science and Agriculture 35-39.

[24] Phung, T.N.H., Coute, A., Bourrelly, P. , 1992. Les Cyanophycées du delta du Mékong Vietnam. Nova Hedwigia 54: 403-446.

[25] Rohrlack, T., Christoffersen, K., Hansen, P.E., Zhang, W., Czarnecki, O., Henning, M., Fastner, J., Erhard, M., Neilan, B.A., Kaebernick, M., 2003. Isolation, characterization, and quantitative analysis of microviridin J, a new Microcystis metabolite toxic to Daphnia. Journal of Chemical Ecology 29:17571769.

[26] Shirota, A., 1966. The plankton of South Vietnam Freshwater and marine plankton. Overseas Technical Cooperation Agency, Japan, 1-462.

[27] Stearns, S. C. 1992. The evolution of life histories. Oxford University Press, Oxford, UK.

[28] Trubetskova, I.L., Haney, J.F., 2006. Effects of differing concentrations of microcystin-producing $\mathrm{Mi}$ crocystis aeruginosa on growth, reproduction, survivorship and offspring of Daphnia magna. Archiv fur Hydrobiologie 167, 533-546.

[29] Sivonen, K., Jones, G., 1999. Cyanobacterial toxins. In: Chorus, I., Bartram, J. (Eds.), Toxic Cyanobacteria in Water - a Guide to Their Public Health Consequences, Monitoring and Management. E \& FN Spon, London, pp. 41-111.

[30] Vasconcelos, V. M., Sivonen, K., Evans, W. R., Carmichael, W. W., \& Namikoshi, M., 1996. Hepatotoxic microcystin diversity in cyanobacterial blooms collected in portuguese freshwa-ters. Water Research 30, 2377-2384.

[31] Von Elert, E., 2002. Determination of limiting polyunsaturated fatty acids in Dapnia galeata using a new method to enrich food algae with singal fatty acids. Limnology and Oceanography 47, 1764-1773

[32] Zhang X, Xie P, Wang W, Li D, Shi Z., 2007. Plasma biochemical responses of the omnivorous crucian carp (Carassius auratus) to crude cyanobacterial extracts. Fish Physiology and Biochemistry 34, 323329 . 